\title{
Nutritional, phytochemical and antioxidant properties of 24 mung bean (Vigna radiate L.) genotypes
}

\author{
Fuhao Wang ${ }^{1,2+}{ }^{+}$Lu Huang $^{1+}$, Xingxing Yuan ${ }^{1}$, Xiaoyan Zhang ${ }^{1}$, Luping Guo ${ }^{3}$, Chenchen Xue ${ }^{1 *}$ and Xin Chen ${ }^{1,2,3^{*}}$ (D)
}

\begin{abstract}
This study aimed to investigate the proximate and phytochemicals present in seeds of 24 mung bean (Vigna radiate L.) genotypes from four provinces of China for estimating their nutritional and antioxidant properties. Proximate analysis of mung bean genotypes revealed that starch, protein, fat, ash and water-soluble polysaccharide ranged from 39.54$60.66,17.36-24.89,4.24-12.18,2.78-3.53$ and $1.99-2.96 \mathrm{~g} / 100 \mathrm{~g}$ respectively. The five principal fatty acids detected in mung beans were stearic acid, palmitic acid, linoleic acid, oleic acid, and linolenic acid. The contents of insolublebound phenolic compounds, soluble phenolic compounds, and flavonoids ranged from 0.78 to $1.5 \mathrm{mg} \mathrm{GAE} \mathrm{g}^{-1}, 1.78$ to $4.10 \mathrm{mg} \mathrm{GAE} \mathrm{g}^{-1}$, and 1.25 to $3.52 \mathrm{mg} \mathrm{RE} \mathrm{g}^{-1}$, respectively. The black seed coat mung bean genotype M13 (Suheilv 1) exhibited highest flavonoid and phenolic contents which showed strong antioxidant activity. Two flavonoids (vitexin and isovitexin) and four phenolic acids (caffeic, syringic acid, p-coumaric, and ferulic acids) were identified by HPLC. Vitexin and isovitexin were the major phenolic compounds in all mung bean genotypes. The content of soluble phenolic compounds had positive correlation with DPPH $\left(r^{2}=0.713\right)$ and ABTS $\left(r^{2}=0.665\right)$ radical scavenging activities. Principal component analysis indicated that the first two principal components could reflect most details on mung bean with a cumulative contribution rate of $66.1 \%$. Twenty-four mung bean genotypes were classified into four groups based on their phenolic compounds contents and antioxidant activities. The present study highlights the importance of these mung bean genotypes as a source of nature antioxidant ingredient for the development of functional foods or a source of health promoting food.
\end{abstract}

Keywords: Phytochemicals, Antioxidant properties, Proximate analysis, Mung bean genotypes, Principal component analysis

\section{Introduction}

Mung bean (Vigna radiate L.) is a species of Fabaceae plant which is well-known as green gram (Ganesan \& Xu 2018). It has been widely grown in the Southeast Asia and is very common in consumer products around the world. Mung beans are rich in protein, starch, cellulose, minerals, and vitamins (Khaket et al. 2015). Studies have shown that mung bean has physiological functions such as antiobesity, anti-oxidation, and anti-bacterial (Yao et al.,

\footnotetext{
* Correspondence: xuecc@jaas.ac.cn; cx@jaas.ac.cn

${ }^{\dagger}$ Fuhao Wang and Lu Huang contributed equally to this work.

'Institute of Industrial Crops, Jiangsu Academy of Agricultural Sciences,

Nanjing, Jiangsu, China

Full list of author information is available at the end of the article
}

2013). Mung bean provides a high-quality natural plant protein source which has been used as a substitute for meat and milk protein in many underdeveloped countries (Connolly et al. 2015; Du et al. 2018). Studies have shown that mung bean polysaccharide has antioxidant and immunomodulatory activities (Lai et al. 2010). Moreover, the essential fatty acids (FAs) contained in mung beans can promote the growth and development of the body. In addition to its nutritional importance, mung beans are a rich source of phytochemicals including phenols and flavonoids that show health promoting effects such as antioxidants, anti-tumor and anti-radiation (Randhir \& Shetty 2007; Soucek et al. 2005). Phenolic phytochemicals are the

(c) The Author(s). 2021 Open Access This article is licensed under a Creative Commons Attribution 4.0 International License, which permits use, sharing, adaptation, distribution and reproduction in any medium or format, as long as you give appropriate credit to the original author(s) and the source, provide a link to the Creative Commons licence, and indicate if changes were made. The images or other third party material in this article are included in the article's Creative Commons licence, unless indicated otherwise in a credit line to the material. If material is not included in the article's Creative Commons licence and your intended use is not permitted by statutory regulation or exceeds the permitted use, you will need to obtain permission directly from the copyright holder. To view a copy of this licence, visit http://creativecommons.org/licenses/by/4.0/. 
largest category of phytochemicals and the most widely distributed in plant (King \& Young 1999). They mainly exist in free, soluble bound and insoluble bound forms (Alshikh et al. 2015; Jung et al. 2002).

Mung beans are commonly consumed food legume in Asian countries. Seeds of mung beans have been used to prepare a variety of fresh, fermented and dried foods. They are very popular foods in China and are known as "green pearls." Mung beans are often used in food processing, such as mung bean porridge, mung bean soup, bean paste, mung bean cake, and raw bean sprouts. They can also be used as jelly, noodles, and vermicelli due to their high starch content. In addition, they are good raw materials for famous wines. Mung bean protein has excellent functional properties such as solubility, water retention, emulsification, gelation, foaming, and foam stability. It has application prospects in flour products, meat products, dairy products, and beverages in the food processing industry. Protein beverages (protein milk, coffee bean milk) made from protein isolates have high nutritional value and high-quality.

Following a country-wide collection during the 1980's, more than 5000 accessions of mung bean germplasm have been deposited in the National Crop Genebank of China (Liu et al. 2006; Wang et al. 2018). In despite of the abundant germplasm resources of mung bean, the diversity of nutritional composition is still unknown. Due to importance of mung bean and its products, it is necessary to investigate nutritional and phytochemical compounds across various genotypes. In this study, 24 mung beans genotypes from four provinces in China were collected for the following purposes: (1) compare their nutritional compositions, (2) analyze their phytochemicals contents, and (3) evaluate correlations between phytochemical compounds and antioxidant activities. Results of this study will provide a good basis for the assessment and application of different mung bean genotypes.

\section{Materials and methods}

Materials

Twenty-four mung bean genotypes (Fig. 1) were collected from four provinces: Shanxi (north of China), Shaanxi (northwest of China), Jiangsu (east of China), and Hebei (north of China). We selected six mung bean genotypes per province. Among them, M12-M18 genotypes come from our lab. Name and geographical origin

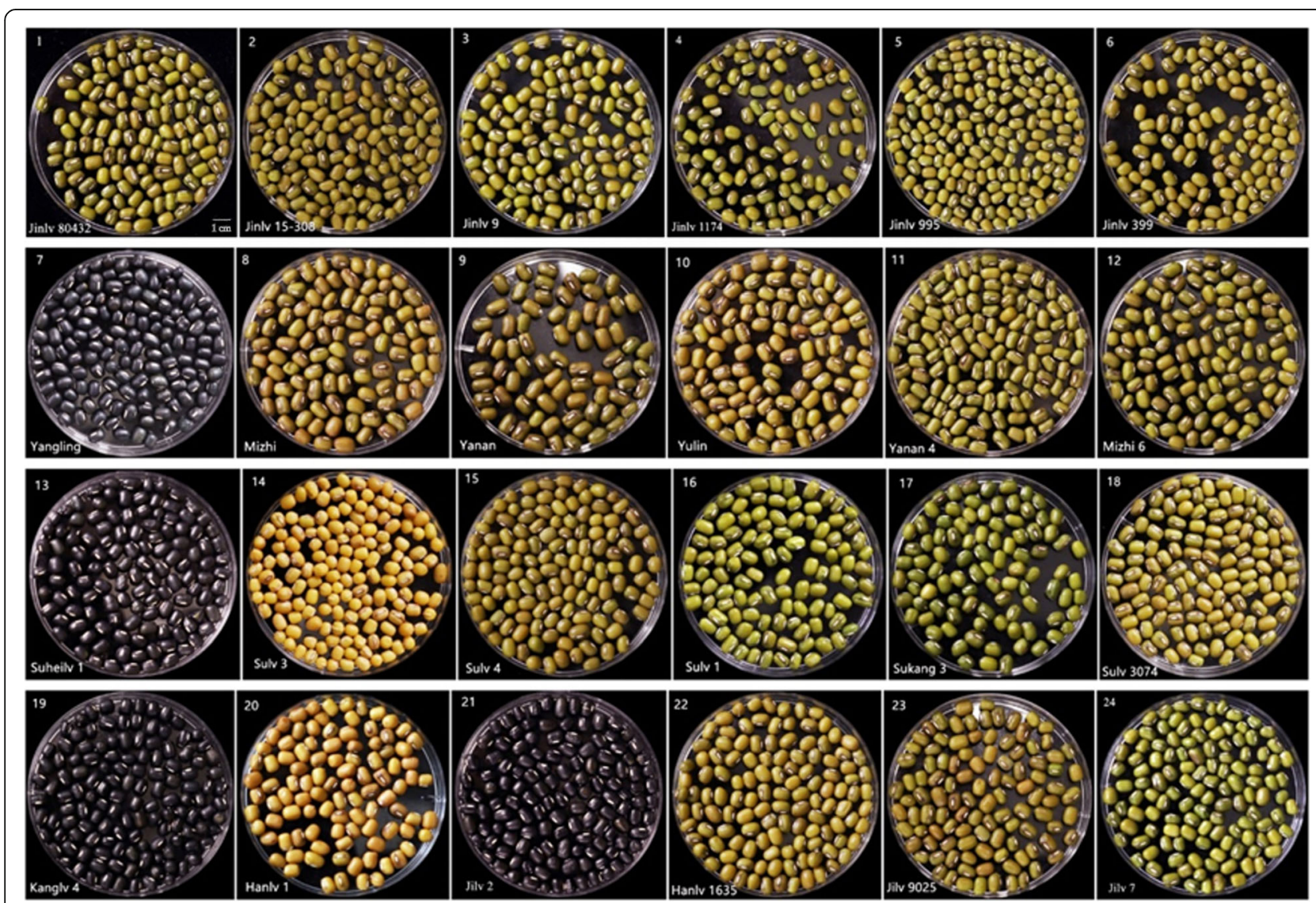

Fig. 1 Photos of 24 mung bean genotypes (M1-24) 
of these genotypes are presented in Table 1 . Seeds of these genotypes were grown in the Liuhe Base of Jiangsu Academy of Agricultural Sciences.

2, 2-diphenyl-1-picrylhydrazyl (DPPH), 2, 2-azinobis (3-ethylbenzothiazoline-6-sulfonic acid) diammonium salt (ABTS), ascorbic acid (vitamin C, Vc), Folin-Ciocalteu's phenol reagent were purchased from SigmaAldrich Chemical Co. (St. Louis, MO, USA). All other reagents used were of analytical grade and purchased from Sodebio Reagent Co., Ltd. (Nanjing, Jiangsu, China).

\section{Analysis of nutrient components}

Protein content was determined by using Kjeldahl method with Kjeltec TM2300 Auto Sampler System (Foss Analytical, Hillerød, Denmark) (Thiex et al. 2002). Soxhlet extraction (Extraction System B-811, Buchi, Flawil, Sankt Gallen, Switzerland) with petroleum ether was used to determine crude fat content (AOAC 1990). Ash content was determined by using the combustion method with an electric muffle furnace (SX2-4-13, Leiyun Instruments, Shanghai, China) (AOAC 1990).

Table 1 Name and geographical origin of the 24 mung bean genotypes

\begin{tabular}{|c|c|c|}
\hline No. & Genotype name & Source/Origin \\
\hline M1 & Jinlv 80432 & Shanxi province \\
\hline M2 & Jinlv 15-308 & Shanxi province \\
\hline M3 & Jinlv 9 & Shanxi province \\
\hline M4 & Jinlv 1174 & Shanxi province \\
\hline M5 & Jinlv 995 & Shanxi province \\
\hline M6 & Jinlv 399 & Shanxi province \\
\hline M7 & Yangling & Shaanxi province \\
\hline M8 & Mizhi & Shaanxi province \\
\hline M9 & Yanan & Shaanxi province \\
\hline M10 & Yulin & Shaanxi province \\
\hline M 11 & Yanan 4 & Shaanxi province \\
\hline M12 & Mizhi 6 & Shaanxi province \\
\hline M13 & Suheilv 1 & Jiangsu province \\
\hline M14 & Sulv 3 & Jiangsu province \\
\hline M15 & Sulv 4 & Jiangsu province \\
\hline M16 & Sulv 1 & Jiangsu province \\
\hline M17 & Sukang 3 & Jiangsu province \\
\hline M18 & Sulv 3074 & Jiangsu province \\
\hline M19 & Kanglv 4 & Hebei province \\
\hline M20 & Hanlv 1 & Hebei province \\
\hline M21 & Jilv 2 & Hebei province \\
\hline M22 & Hanlv 1635 & Hebei province \\
\hline M23 & Jilv 9025 & Hebei province \\
\hline M24 & Jilv 7 & Hebei province \\
\hline
\end{tabular}

Starch content was determined using a starch kit (BC0700, Solarbio Science \& Technology Co., Ltd., Beijing, China).

\section{Fatty acid composition}

Fatty acid (FA) composition was determined according to the method of Zhang et al. (2013) with slight modifications. Briefly, $0.5 \mathrm{~g}$ mung bean powder was added in a $2 \mathrm{~mL}$ centrifuge tube with $1.5 \mathrm{~mL}$-hexane. The mixture was left overnight and then centrifuged at $8200 \mathrm{~g}$ for 5 min (Eppendorf Centrifuge 5804R, Hamburg, Germany). Then, $350 \mu \mathrm{L}$ of sodium methoxide solution was added and vortexed for $1 \mathrm{~h}$. After centrifugation, the supernatant was as used for high-performance gas chromatography analysis (Agilent 7890B, Agilent Technologies Inc., Wilmington, DE, USA).

\section{Determination of water-soluble polysaccharide (WSP)}

The WSP was determined according to Yao et al. (2016) with several modifications. The mung bean powder was extracted with $80 \%$ ethanol for $1 \mathrm{~h}$ and then centrifuged at $2000 \mathrm{~g}$ for $5 \mathrm{~min}$. The supernatant was removed and extracted twice with distilled water at $90^{\circ} \mathrm{C}$ for $3 \mathrm{~h}$. After centrifugation, the supernatant was collected with Sevag reagent (chloroform:n-butanol $=4: 1, \mathrm{v} / \mathrm{v}$ ) and shaken for $10 \mathrm{~min}$. The mixture was centrifuged at $2000 \mathrm{~g}$ for $5 \mathrm{~min}$. The lower organic solvent and protein at the interface were then removed. The gelatin was denatured, and the upper polysaccharide solution was retained.

Preparation of standard curve: $10 \mathrm{mg}$ of glucose standard solution was accurately weighed and dissolved in 10 $\mathrm{mL}$ to obtain $1 \mathrm{mg} / \mathrm{mL}$ glucose standard solution. The solution was diluted to $10,20,40,60,80$, and $100 \mu \mathrm{g} /$ $\mathrm{mL}$. Then, $1.0 \mathrm{~mL}$ of the diluted solution was drawn, and $1 \mathrm{~mL}$ of distilled water was added. Immediately thereafter, $1.0 \mathrm{~mL}$ of a $6 \%$ phenol solution was added, and 5.0 $\mathrm{mL}$ of concentrated sulfuric acid was slowly added and shaken while adding. After mixing well, the solution was left to stand at room temperature for $20 \mathrm{~min}$. The absorbance of the solution was measured at $490 \mathrm{~nm}$ by a spectrophotometer (Alpha-1101 m, Puyuan Instruments, Shanghai, China). Next, $1.0 \mathrm{~mL}$ of polysaccharide sample solution with certain concentration was drawn, and distilled water was added to make it $2.0 \mathrm{~mL}$. The subsequent operation was the same as glucose labeling. The purity of the corresponding polysaccharide was calculated according to its absorbance value and standard curve.

\section{Extract analysis Preparation of ethanol extracts}

Mung bean powder $(1 \mathrm{~g})$ was mixed with $25 \mathrm{~mL}$ of $80 \%$ ethanol solution and extracted in a water bath for $4 \mathrm{~h}$. The solution was cooled to room temperature and 
centrifuged at $15000 \mathrm{~g}$ for $15 \mathrm{~min}$. The operation was repeated 2-3 times, and the obtained supernatant was mixed and concentrated. The volume was made to reach $20 \mathrm{~mL}$ with methanol and stored at $-20^{\circ} \mathrm{C}$ for testing. The collected supernatants were examined for soluble phenolic compounds.

\section{Determination of total flavonoid content}

Total flavonoid content (TFC) was determined according to the method reported by Xie et al. (2015). The sample extract $(250 \mu \mathrm{L})$ was mixed with $1.25 \mathrm{~mL}$ of distilled water, and $25 \mu \mathrm{L}$ of $5 \% \mathrm{NaNO}_{2}$ was added to react for $6 \mathrm{~min}$. Then, $150 \mu \mathrm{L}$ of $10 \% \mathrm{AlCl}_{3}$ was added to react for $5 \mathrm{~min}$. Finally, $0.5 \mathrm{~mL}$ of $1 \mathrm{M} \mathrm{NaOH}$ and $275 \mu \mathrm{L}$ of distilled water were added to the mixture, and the absorbance was measured at $510 \mathrm{~nm}$ after $10 \mathrm{~min}$. Rutin with different concentrations was plotted as the standard curve, and the results were expressed as rutin equivalents (RE).

\section{The content of soluble phenolic compounds}

The content of soluble phenolic compounds in the samples was determined by using the Folin-Ciocalteu method. The sample solution $(400 \mu \mathrm{L})$ and $4.6 \mathrm{~mL}$ of deionized water were placed in a test tube, and $1 \mathrm{~mL}$ of Folin-Ciocalteu and $24 \mathrm{~mL}$ of $7.5 \%(\mathrm{w} / \mathrm{v})$ of sodium carbonate solution were injected into the test tube. After reacting for $2 \mathrm{~h}$ at room temperature, the absorbance of the sample was measured at a wavelength of $760 \mathrm{~nm}$. The standard curve was configured with different concentrations of gallic acid, and the results were expressed as gallic acid equivalents (GAE).

\section{The content of insoluble-bound phenolic compounds}

Extraction of insoluble-bound phenolic compounds was performed according to the method reported by Zhang et al. (2013). Briefly, $20 \mathrm{~mL}$ of $\mathrm{NaOH}(2 \mathrm{~mol} / \mathrm{L})$ was mixed with the residue left after extracting soluble phenolic compounds and incubated for $1 \mathrm{~h}$ at room temperature. The mixture was centrifuged at $4500 \mathrm{~g}$ for $5 \mathrm{~min}$, and the supernatant was extracted and adjusted to $\mathrm{pH} 2$ with $\mathrm{HCl}(6 \mathrm{~mol} / \mathrm{L})$. Then, an equal volume of ethyl acetate was added for extraction, and the extraction was repeated 3 times. The extract was mixed, evaporated to dryness by a rotary evaporator at $45{ }^{\circ} \mathrm{C}$, reconstituted to $5 \mathrm{~mL}$ of methanol, and determined by using the Folin-Ciocalteu method.

High-performance liquid chromatography (HPLC) analysis of phenolic compounds

Agilent 1260 high performance liquid chromatography (Agilent Technologies Inc. Santa Clara, CA, USA) equipped with the Agilent Poroshell 120 EC-C18 Column was used to detect the main phenolic compounds in mung bean seeds. The mobile phase consisted of acetonitrile (A) and ultrapure water containing $0.1 \%$ trifluoroacetic acid (B). Gradient elution was performed as follows: 0-7 min, 5-30\% A; 7-15 min, 3040\% A; $15-25 \mathrm{~min}, 40-50 \%$ A; $25-30 \mathrm{~min}, 50-95 \%$ A; $30-35 \mathrm{~min}, 95-5 \% \mathrm{~A}$. The flow rate was set at $1.0 \mathrm{~mL}$ $\min ^{-1}$ and the injection volume was $10 \mu \mathrm{L}$. The column was operated at $30^{\circ} \mathrm{C}$. The wavelength of the detector was set at $280 \mathrm{~nm}$. Quantification of phenolic compounds was carried out by an external standard method using calibration curves.

\section{Evaluation of antioxidant capacity Assay of DPPH radical scavenging activity}

$\mathrm{DPPH}$ analysis was executed in line with the report of Chai et al. (2018). Briefly, DPPH was dissolved in methanol. Then, $0.5 \mathrm{~mL}$ of DPPH $(0.4 \mathrm{mmol} / \mathrm{L})$ and $0.5 \mathrm{~mL}$ of the extract were mixed to react in the dark at room temperature for $30 \mathrm{~min}$. The absorbance was measured at $517 \mathrm{~nm}$ with a spectrophotometer. The results were expressed as $\mu \mathrm{mol}$ vitamin $C$ per gram samples.

\section{Assay of ABTS radical cation scavenging activity}

ABTS radical cation scavenging assay was performed according to the method reported by Lee et al. (2011) with some modifications. ABTS radical ions were produced by mixing $7 \mathrm{mM}$ ABTS aqueous solution with $2.45 \mathrm{mM} \mathrm{K} \mathrm{K}_{2} \mathrm{~S}_{2} \mathrm{O}_{8}$ aqueous solution, storing in the dark for $16 \mathrm{~h}$, diluting 20 times with absolute ethanol before use, and storing at $30{ }^{\circ} \mathrm{C}$. Next, $1.2 \mathrm{~mL}$ of ABTS ethanol solution was mixed with $300 \mu \mathrm{L}$ of extract to react at $30^{\circ} \mathrm{C}$ for $6 \mathrm{~min}$. The absorbance was measured at 734 $\mathrm{nm}$ with a spectrophotometer. The results were expressed as $\mu \mathrm{mol}$ vitamin $\mathrm{C}$ per gram.

\section{Hydroxyl radical scavenging ability}

The hydroxyl radical scavenging ability was determined according to Xiao et al. (2015) with simple modifications. Briefly, $300 \mu \mathrm{L}$ of $\mathrm{FeSO}_{4}(9 \mathrm{mmol} / \mathrm{L}), 300 \mu \mathrm{L}$ of $\mathrm{H}_{2} \mathrm{O}_{2}$ and $300 \mu \mathrm{L}$ of the extract were mixed. After shaking, the mixture was added with $300 \mu \mathrm{L}$ of salicylic acidethanol $(9 \mathrm{mmol} / \mathrm{L})$ and incubated at $37^{\circ} \mathrm{C}$ for $30 \mathrm{~min}$. The absorbance was measured at $510 \mathrm{~nm}$. The results were expressed as $\mu \mathrm{mol}$ vitamin $\mathrm{C}$ per gram samples.

\section{Statistical analysis}

All experiments were conducted in triplicate and results were expressed as mean \pm standard deviation. The statistical significance of the results was obtained by one-way analysis of variance and PCA using SPSS version 21.0 software. The Pearson correlation coefficient was used to estimate the correlation between phytochemical compounds and antioxidant activities. PCA was used to 
assess the contribution of chemical components to mung beans.

\section{Results and discussion Nutritional compositions}

Protein and starch are the two most abundant nutritional components in mung bean seed. In this study, the protein and starch contents of 24 mung bean genotypes ranged from 17.36 to $24.89 \mathrm{~g} / 100 \mathrm{~g}$ and $39.54 \mathrm{~g} / 100 \mathrm{~g}$ to $60.66 \mathrm{~g} /$ $100 \mathrm{~g}$ (Table 2), respectively. M6 (Jinlv 399) showed the highest contents of protein $(24.89 \mathrm{~g} / 100 \mathrm{~g})$ and starch $(60.66 \mathrm{~g} / 100 \mathrm{~g})$ which could be used for specific food processing, such as noodles and vermicelli. Compared with other legumes, mung beans have a higher carbohydrate content, predominantly starch (Tang et al. 2014). The contributions of ash were in the ranges of 2.78 to $3.53 \mathrm{~g} / 100 \mathrm{~g}$. The content of water-soluble polysaccharide (WSP) ranged from 1.99 to $2.96 \mathrm{~g} / 100 \mathrm{~g}$. M14 (Sulv 3) exhibited the highest content of WSP, while M2 showed the lowest value. The biological activity of polysaccharides has received attention, such as antioxidant and immunological activities.
Table 2 shows the crude fat content and FA composition of 24 kinds of mung beans. The content of crude fat ranged from 4.24 to $12.18 \mathrm{mg} / \mathrm{g}$. High-performance gas chromatography was used for the analysis of FA in mung bean. Five principal FAs were observed and identified according to standards (Fig. 2). Peaks 1, 2, 3, 4 and 5 with the retention time of 2.402, 3.187, 3.318, 3.602 and $3.953 \mathrm{~min}$ were referred to as palmitic acid, stearic acid, oleic acid, linoleic acid and linolenic acid, respectively. Linoleic acid was the most abundant in mung bean and accounted for 38.95-44.74 percentage of the total fatty acids. A similar observation was reported by Anwar et al. (2007) who investigated fatty acid composition of different mung bean cultivars grown in Pakistan. Studies have shown that polyunsaturated fatty acids are important structural substances in the retina and neurons which can protect the vision. Polyunsaturated fatty acids have important physiological functions in human metabolism, such as esterification of cholesterol, lowering blood cholesterol and triglycerides (Yates et al. 2014).

Table 2 Proximate analysis of different mung bean genotypes

\begin{tabular}{|c|c|c|c|c|c|c|c|c|c|c|}
\hline No. & $\begin{array}{l}\text { Starch g/ } \\
100 \mathrm{~g}\end{array}$ & $\begin{array}{l}\text { Protein g/ } \\
100 \mathrm{~g}\end{array}$ & $\begin{array}{l}\text { Ash g/ } \\
100 \mathrm{~g}\end{array}$ & $\begin{array}{l}\text { WSP g/ } \\
100 \mathrm{~g}\end{array}$ & Fat $\mathrm{mg} / \mathrm{g}$ & $\begin{array}{l}\text { Palmitic acid } \\
\text { (\%) }\end{array}$ & $\begin{array}{l}\text { Stearic acid } \\
\text { (\%) }\end{array}$ & $\begin{array}{l}\text { Oleic acid } \\
(\%)\end{array}$ & $\begin{array}{l}\text { Linoleic acid } \\
\text { (\%) }\end{array}$ & $\begin{array}{l}\text { Linolenic acid } \\
\text { (\%) }\end{array}$ \\
\hline M1 & $53.60 \pm 0.30$ & $22.54 \pm 0.46$ & $3.15 \pm 0.03$ & $2.13 \pm 0.10$ & $7.98 \pm 0.23$ & $27.33 \pm 0.60$ & $7.74 \pm 0.55$ & $8.17 \pm 1.05$ & $38.95 \pm 0.39$ & $17.81 \pm 0.22$ \\
\hline M2 & $50.52 \pm 0.88$ & $24.36 \pm 0.31$ & $3.48 \pm 0.07$ & $1.99 \pm 0.16$ & $10.53 \pm 0.88$ & $25.92 \pm 0.19$ & $8.22 \pm 0.05$ & $6.19 \pm 0.38$ & $41.61 \pm 0.30$ & $18.06 \pm 0.22$ \\
\hline M3 & $45.65 \pm 0.84$ & $24.63 \pm 0.21$ & $3.08 \pm 0.03$ & $2.28 \pm 0.20$ & $7.79 \pm 0.31$ & $24.87 \pm 0.03$ & $6.83 \pm 0.01$ & $5.23 \pm 0.03$ & $40.85 \pm 0.02$ & $22.23 \pm 0.03$ \\
\hline M4 & $44.64 \pm 0.58$ & $17.36 \pm 0.34$ & $3.46 \pm 0.06$ & $2.53 \pm 0.10$ & $6.95 \pm 0.42$ & $24.83 \pm 0.00$ & $6.82 \pm 0.01$ & $5.26 \pm 0.01$ & $40.87 \pm 0.04$ & $22.21 \pm 0.05$ \\
\hline M5 & $39.63 \pm 0.69$ & $22.34 \pm 0.27$ & $2.89 \pm 0.04$ & $2.44 \pm 0.21$ & $7.02 \pm 0.19$ & $26.70 \pm 0.02$ & $6.16 \pm 0.08$ & $3.69 \pm 0.00$ & $44.74 \pm 0.09$ & $18.70 \pm 0.05$ \\
\hline M6 & $60.66 \pm 0.49$ & $24.89 \pm 0.10$ & $3.14 \pm 0.06$ & $2.22 \pm 0.19$ & $12.18 \pm 0.15$ & $27.41 \pm 0.17$ & $7.10 \pm 0.09$ & $3.95 \pm 0.18$ & $42.90 \pm 0.03$ & $18.73 \pm 0.05$ \\
\hline M7 & $60.49 \pm 0.49$ & $19.70 \pm 0.27$ & $3.25 \pm 0.05$ & $2.22 \pm 0.14$ & $6.55 \pm 0.17$ & $26.78 \pm 0.35$ & $7.25 \pm 0.16$ & $5.55 \pm 0.08$ & $41.20 \pm 0.25$ & $19.22 \pm 0.22$ \\
\hline M8 & $46.37 \pm 0.89$ & $20.51 \pm 0.00$ & $2.94 \pm 0.01$ & $2.49 \pm 0.20$ & $8.05 \pm 1.68$ & $25.81 \pm 0.08$ & $6.37 \pm 0.07$ & $3.94 \pm 0.07$ & $44.20 \pm 0.13$ & $19.67 \pm 0.07$ \\
\hline M9 & $49.21 \pm 1.20$ & $22.42 \pm 0.48$ & $3.21 \pm 0.01$ & $2.24 \pm 0.16$ & $7.73 \pm 0.05$ & $25.83 \pm 0.21$ & $5.24 \pm 0.09$ & $2.69 \pm 0.11$ & $43.66 \pm 0.27$ & $22.57 \pm 0.30$ \\
\hline M10 & $42.09 \pm 0.80$ & $22.09 \pm 0.28$ & $3.27 \pm 0.02$ & $2.48 \pm 0.37$ & $6.71 \pm 0.41$ & $25.89 \pm 0.04$ & $6.24 \pm 0.13$ & $4.25 \pm 0.08$ & $42.54 \pm 0.12$ & $21.08 \pm 0.05$ \\
\hline M11 & $58.90 \pm 1.12$ & $20.33 \pm 0.05$ & $3.11 \pm 0.09$ & $2.22 \pm 0.10$ & $6.85 \pm 0.27$ & $26.08 \pm 0.17$ & $5.77 \pm 0.05$ & $3.52 \pm 0.16$ & $41.48 \pm 0.19$ & $23.14 \pm 0.20$ \\
\hline M12 & $57.79 \pm 0.99$ & $20.76 \pm 0.18$ & $3.24 \pm 0.15$ & $2.04 \pm 0.12$ & $7.75 \pm 0.38$ & $24.87 \pm 0.16$ & $5.77 \pm 0.08$ & $2.91 \pm 0.13$ & $43.88 \pm 0.19$ & $22.58 \pm 0.19$ \\
\hline M13 & $39.85 \pm 0.90$ & $21.92 \pm 0.25$ & $2.78 \pm 0.09$ & $2.71 \pm 0.17$ & $6.40 \pm 0.26$ & $25.28 \pm 0.27$ & $5.18 \pm 0.12$ & $2.74 \pm 0.10$ & $42.37 \pm 0.24$ & $24.43 \pm 0.34$ \\
\hline M14 & $39.54 \pm 1.17$ & $21.42 \pm 0.10$ & $3.10 \pm 0.13$ & $2.96 \pm 0.04$ & $6.79 \pm 0.18$ & $26.16 \pm 0.04$ & $4.99 \pm 0.09$ & $2.96 \pm 0.12$ & $39.99 \pm 0.05$ & $25.89 \pm 0.13$ \\
\hline M15 & $41.98 \pm 0.89$ & $22.70 \pm 0.26$ & $3.31 \pm 0.09$ & $2.20 \pm 0.35$ & $8.17 \pm 0.32$ & $25.89 \pm 0.15$ & $5.90 \pm 0.03$ & $3.75 \pm 0.09$ & $44.63 \pm 0.12$ & $19.82 \pm 0.03$ \\
\hline M16 & $45.97 \pm 0.80$ & $21.41 \pm 0.31$ & $3.53 \pm 0.11$ & $2.62 \pm 0.18$ & $4.24 \pm 0.13$ & $24.85 \pm 0.03$ & $6.82 \pm 0.01$ & $5.22 \pm 0.05$ & $40.88 \pm 0.06$ & $22.23 \pm 0.02$ \\
\hline M17 & $42.16 \pm 0.72$ & $22.89 \pm 0.31$ & $3.53 \pm 0.07$ & $2.63 \pm 0.09$ & $9.62 \pm 0.41$ & $24.82 \pm 0.00$ & $6.83 \pm 0.01$ & $5.26 \pm 0.01$ & $40.85 \pm 0.02$ & $22.24 \pm 0.01$ \\
\hline M18 & $45.32 \pm 0.32$ & $22.75 \pm 0.79$ & $3.29 \pm 0.04$ & $2.35 \pm 0.13$ & $10.87 \pm 0.08$ & $24.81 \pm 0.01$ & $6.82 \pm 0.01$ & $5.27 \pm 0.00$ & $40.86 \pm 0.00$ & $22.24 \pm 0.01$ \\
\hline M19 & $45.49 \pm 0.33$ & $21.32 \pm 0.27$ & $2.97 \pm 0.06$ & $2.09 \pm 0.45$ & $9.73 \pm 0.27$ & $25.65 \pm 0.06$ & $5.88 \pm 0.20$ & $4.61 \pm 0.21$ & $43.75 \pm 0.16$ & $20.11 \pm 0.13$ \\
\hline M20 & $49.32 \pm 0.55$ & $22.08 \pm 0.06$ & $3.49 \pm 0.07$ & $2.23 \pm 0.33$ & $6.70 \pm 0.15$ & $25.22 \pm 0.82$ & $6.34 \pm 0.89$ & $4.42 \pm 1.09$ & $41.47 \pm 0.84$ & $22.55 \pm 0.32$ \\
\hline M21 & $49.39 \pm 0.94$ & $21.87 \pm 0.14$ & $3.21 \pm 0.10$ & $2.40 \pm 0.11$ & $9.70 \pm 0.10$ & $24.85 \pm 0.03$ & $6.82 \pm 0.01$ & $5.05 \pm 0.01$ & $40.99 \pm 0.01$ & $22.29 \pm 0.02$ \\
\hline M22 & $52.26 \pm 0.30$ & $23.08 \pm 0.24$ & $3.23 \pm 0.08$ & $2.28 \pm 0.05$ & $8.18 \pm 0.41$ & $24.82 \pm 0.05$ & $6.84 \pm 0.00$ & $5.04 \pm 0.00$ & $41.02 \pm 0.03$ & $22.28 \pm 0.01$ \\
\hline M23 & $46.64 \pm 0.98$ & $24.10 \pm 0.43$ & $2.88 \pm 0.06$ & $2.54 \pm 0.21$ & $6.98 \pm 0.97$ & $27.82 \pm 0.12$ & $7.27 \pm 0.15$ & $3.96 \pm 0.11$ & $42.57 \pm 0.16$ & $18.37 \pm 0.12$ \\
\hline M24 & $49.44 \pm 0.58$ & $23.45 \pm 0.19$ & $3.28 \pm 0.05$ & $2.86 \pm 0.19$ & $7.62 \pm 0.16$ & $26.59 \pm 0.12$ & $5.72 \pm 0.25$ & $3.54 \pm 0.26$ & $44.50 \pm 0.04$ & $19.64 \pm 0.09$ \\
\hline
\end{tabular}




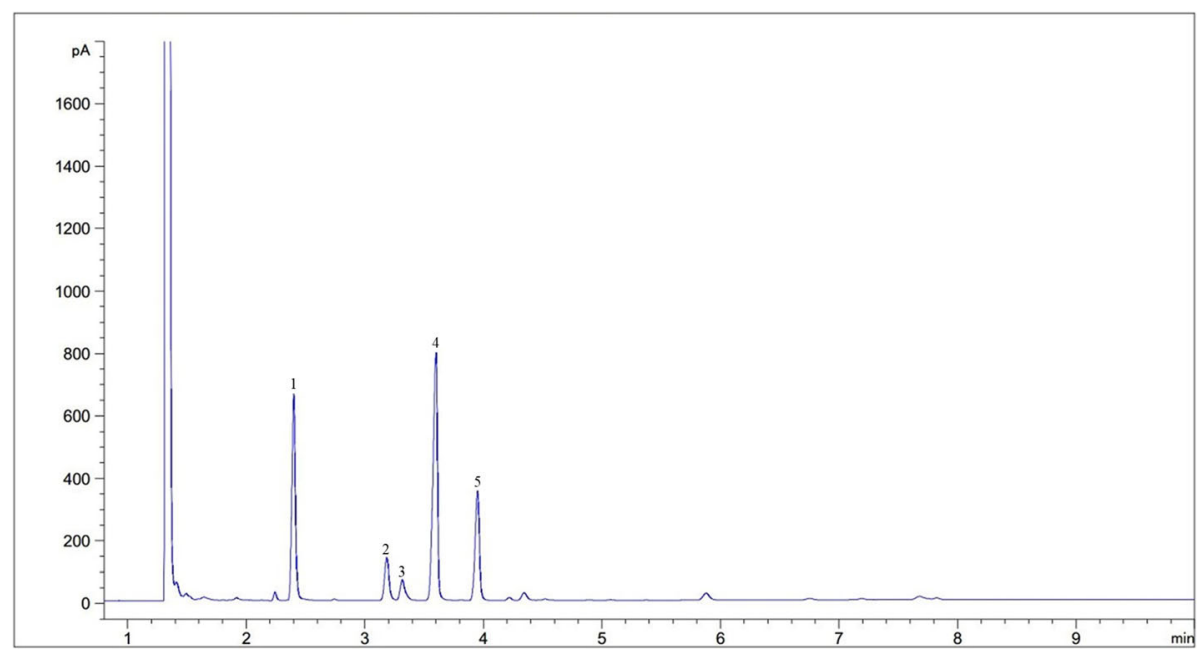

Fig. 2 High performance gas chromatogram of fatty acids in mung bean. Peaks 1, 2, 3, 4 and 5 were identified as palmitic acid, stearic acid, oleic acid, linoleic acid and linolenic acid

Table 3 Contents of phytochemicals of different mung bean genotypes

\begin{tabular}{|c|c|c|c|c|}
\hline No. & $\begin{array}{l}\text { Total flavonoid content } \\
\mathrm{mg} \mathrm{RE} \mathrm{g}^{-1}\end{array}$ & $\begin{array}{l}\text { Soluble phenolic compounds } \\
\mathrm{mg} \mathrm{GAE} \mathrm{g}^{-1}\end{array}$ & $\begin{array}{l}\text { Insoluble-bound phenolic } \\
\text { compounds mg GAE g }\end{array}$ & $\begin{array}{l}\text { Total phenolic content } \\
\text { mg GAE g }\end{array}$ \\
\hline M1 & $1.56 \pm 0.13$ & $2.36 \pm 0.14$ & $0.94 \pm 0.06$ & $3.30 \pm 0.12$ \\
\hline M2 & $1.77 \pm 0.09$ & $2.30 \pm 0.12$ & $0.89 \pm 0.05$ & $3.19 \pm 0.10$ \\
\hline M3 & $1.50 \pm 0.30$ & $2.26 \pm 0.06$ & $0.94 \pm 0.05$ & $3.20 \pm 0.23$ \\
\hline M4 & $1.59 \pm 0.16$ & $1.98 \pm 0.03$ & $1.04 \pm 0.08$ & $3.02 \pm 0.07$ \\
\hline M5 & $1.45 \pm 0.09$ & $2.02 \pm 0.12$ & $1.08 \pm 0.03$ & $3.10 \pm 0.11$ \\
\hline M6 & $2.40 \pm 0.28$ & $2.09 \pm 0.09$ & $1.02 \pm 0.15$ & $3.11 \pm 0.13$ \\
\hline M7 & $1.58 \pm 0.13$ & $2.65 \pm 0.10$ & $1.09 \pm 0.04$ & $3.74 \pm 0.09$ \\
\hline M8 & $1.54 \pm 0.23$ & $2.85 \pm 0.05$ & $0.78 \pm 0.01$ & $2.90 \pm 0.05$ \\
\hline M9 & $1.74 \pm 0.06$ & $2.48 \pm 0.09$ & $0.82 \pm 0.01$ & $3.30 \pm 0.09$ \\
\hline M10 & $1.84 \pm 0.18$ & $2.37 \pm 0.04$ & $0.99 \pm 0.03$ & $3.36 \pm 0.04$ \\
\hline M11 & $1.86 \pm 0.10$ & $2.66 \pm 0.07$ & $1.14 \pm 0.07$ & $3.80 \pm 0.07$ \\
\hline M12 & $1.44 \pm 0.26$ & $2.28 \pm 0.06$ & $1.22 \pm 0.16$ & $3.50 \pm 0.14$ \\
\hline M13 & $3.52 \pm 0.27$ & $4.10 \pm 0.12$ & $1.50 \pm 0.06$ & $5.60 \pm 0.10$ \\
\hline M14 & $1.78 \pm 0.03$ & $2.63 \pm 0.08$ & $1.10 \pm 0.03$ & $3.73 \pm 0.07$ \\
\hline M15 & $1.30 \pm 0.11$ & $1.92 \pm 0.08$ & $1.00 \pm 0.04$ & $2.92 \pm 0.07$ \\
\hline M16 & $1.63 \pm 0.14$ & $2.20 \pm 0.13$ & $1.35 \pm 0.03$ & $3.55 \pm 0.20$ \\
\hline M17 & $1.82 \pm 0.02$ & $2.74 \pm 0.06$ & $0.91 \pm 0.03$ & $3.65 \pm 0.05$ \\
\hline M18 & $1.63 \pm 0.14$ & $2.02 \pm 0.04$ & $1.02 \pm 0.03$ & $3.04 \pm 0.04$ \\
\hline M19 & $1.67 \pm 0.06$ & $2.58 \pm 0.07$ & $1.06 \pm 0.03$ & $3.64 \pm 0.06$ \\
\hline M20 & $1.66 \pm 0.09$ & $2.21 \pm 0.13$ & $1.18 \pm 0.03$ & $3.39 \pm 0.12$ \\
\hline M21 & $1.82 \pm 0.17$ & $2.69 \pm 0.04$ & $0.89 \pm 0.13$ & $3.58 \pm 0.12$ \\
\hline M22 & $1.25 \pm 0.15$ & $1.78 \pm 0.07$ & $1.09 \pm 0.06$ & $2.87 \pm 0.07$ \\
\hline M23 & $1.86 \pm 0.12$ & $2.68 \pm 0.03$ & $1.13 \pm 0.02$ & $3.81 \pm 0.03$ \\
\hline M24 & $2.12 \pm 0.14$ & $2.99 \pm 0.05$ & $1.00 \pm 0.02$ & $3.99 \pm 0.04$ \\
\hline
\end{tabular}

Data are expressed as mean \pm standard deviation of triplicate samples 
Contents of phytochemicals (total flavonoid content, insoluble-bound phenolic content and soluble phenolic content)

As shown in Table 3, the total flavonoid content of 24 mung bean genotypes ranged from 1.25 to $3.52 \mathrm{mg} R E$ $\mathrm{g}^{-1}$. M13 (Suheilv 1) presented the highest flavonoid content (3.52 $\mathrm{mg} \mathrm{RE} \mathrm{g}^{-1}$ ) and M5 (Jinlv 995) presented the lowest flavonoid content. Flavonoids are general name of a group of chemicals including catechins, anthocyanidins, proanthocyanidins, flavonols, isoflavonoids and flavones (Luo et al. 2016). Flavonoids have important physiological functions such as anti-oxidation and anti-inflammatory (Zuk et al. 2019). Zhang et al. (2013) used acetone and water as extraction solvents, and the highest flavonoid content obtained was $6.0 \mathrm{mg}$ $\mathrm{g}^{-1}$. This may be different from the extraction solvent. The nature of the raw materials itself also has a relationship, such as the difference in the color of the skin and the difference in maturity.

The contents of soluble and insoluble-bound phenolic compounds in 24 mung bean genotypes investigated are shown in Table 3. The phenolic content of the soluble fraction ranged from 1.78 to $4.10 \mathrm{mg}$ GAE $\mathrm{g}^{-1}$. Insoluble-bound phenolic content ranged from 0.78 to $1.5 \mathrm{mg}$ GAE $\mathrm{g}^{-1}$. M13 genotype exhibited the highest content of both soluble and insoluble-bound phenolic compounds. Meanwhile, M22 had the lowest soluble phenolic content of $1.78 \mathrm{mg} \mathrm{GAE}^{-1}$ and M8 exhibited the lowest insoluble-bound phenolic content of $0.78 \mathrm{mg}$ $\mathrm{GAE}^{-1}$. The difference between soluble and insolublebound phenolic contents is significant, which is similar to Wang et al. (2016). A similar result was reported by de Camargo et al. (2015) who observed that the content of soluble phenolic compounds (free and esterified) was significantly higher than insoluble-bound fraction in peanut skin. The amount of phenolic compound is affected by genotype, agronomic habits (irrigation, fertilization, and pest management), harvest maturity, post-harvest storage, and climatic conditions (Mattila et al. 2005).

\section{Identification of major phenolic compounds in mung bean seeds}

Soluble and insoluble-bound phenolic compounds in mung bean seeds were identified by HPLC as shown in Fig. 3 and Table 4. Peaks 1, 2, 3, 4, 5 and 6 with the retention time of $17.785,18.534,24.160,29.017$ and 29.731 min were referred to as caffeic acid, syringic acid, $p$-coumaric acid, ferulic acid, vitexin and isovitexin, respectively (Fig. 3). In the present study, six phenolic compounds were identified, including four phenolic acids (syringic, caffeic, $p$-coumaric, and ferulic acids) and two flavonoids (vitexin and isovitexin). Results showed that vitexin and isovitexin were the dominant phenolic compounds in all mung bean genotypes. This is consistent with a previous study (Yang et al. 2020). The vitexin content of soluble and insoluble-bound fractions ranged from 481.02 to $910.26 \mu \mathrm{gg}^{-1}$ and from 123.77 to $463.25 \mathrm{\mu g} \mathrm{g}^{-1}$, respectively. The isovitexin content of soluble and insoluble-bound fractions ranged from 568.57 to $1572.74 \mu \mathrm{g} \mathrm{g}^{-1}$ and from 104.42 to $421.77 \mathrm{\mu g} \mathrm{g}^{-1}$, respectively. The isovitexin content in the soluble fractions of mung bean seeds were higher than their corresponding vitexin content. M13 showed the highest vitexin $\left(910.26{\left.\mu \mathrm{gg}^{-1}\right)}^{-1}\right.$ and isovitexin $\left(1572.74{\left.\mu \mathrm{gg}^{-1}\right)}^{-1}\right.$ contents in the soluble fractions of all studied mung beans. Large differences were found

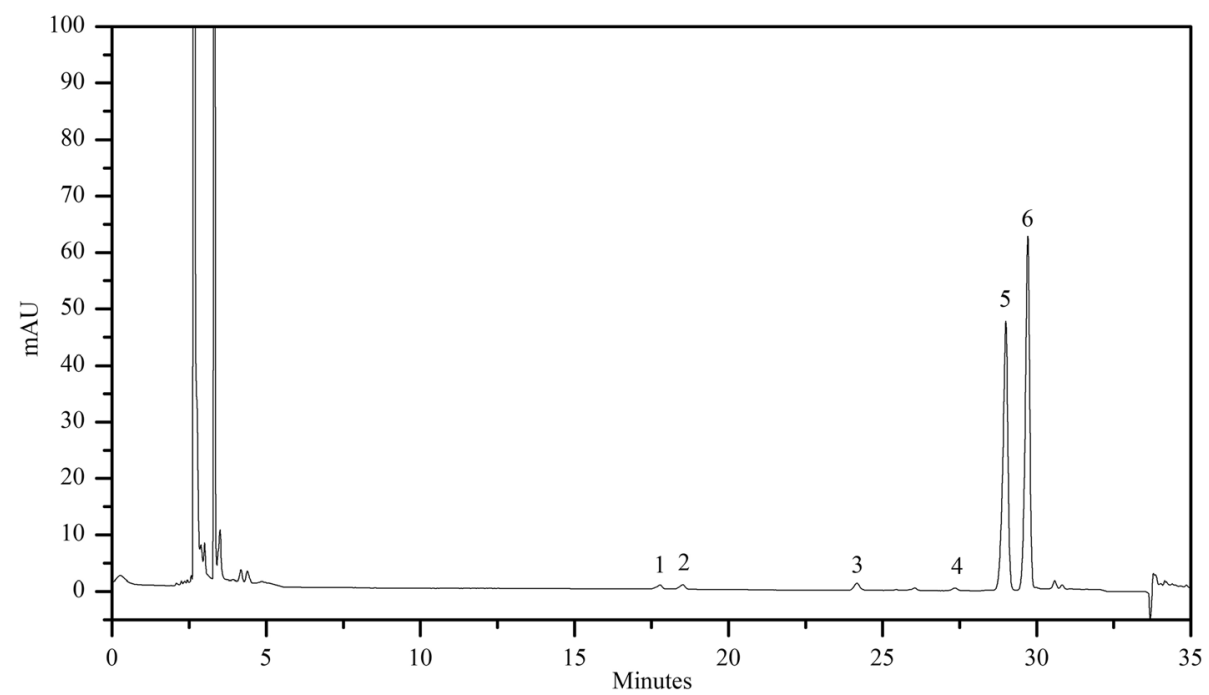

Fig. 3 High-performance liquid chromatogram of phenolic compounds in mung bean. Peaks 1, 2, 3, 4, 5 and 6 were identified as caffeic acid, syringic acid, $p$-coumaric acid, ferulic acid, vitexin and isovitexin 


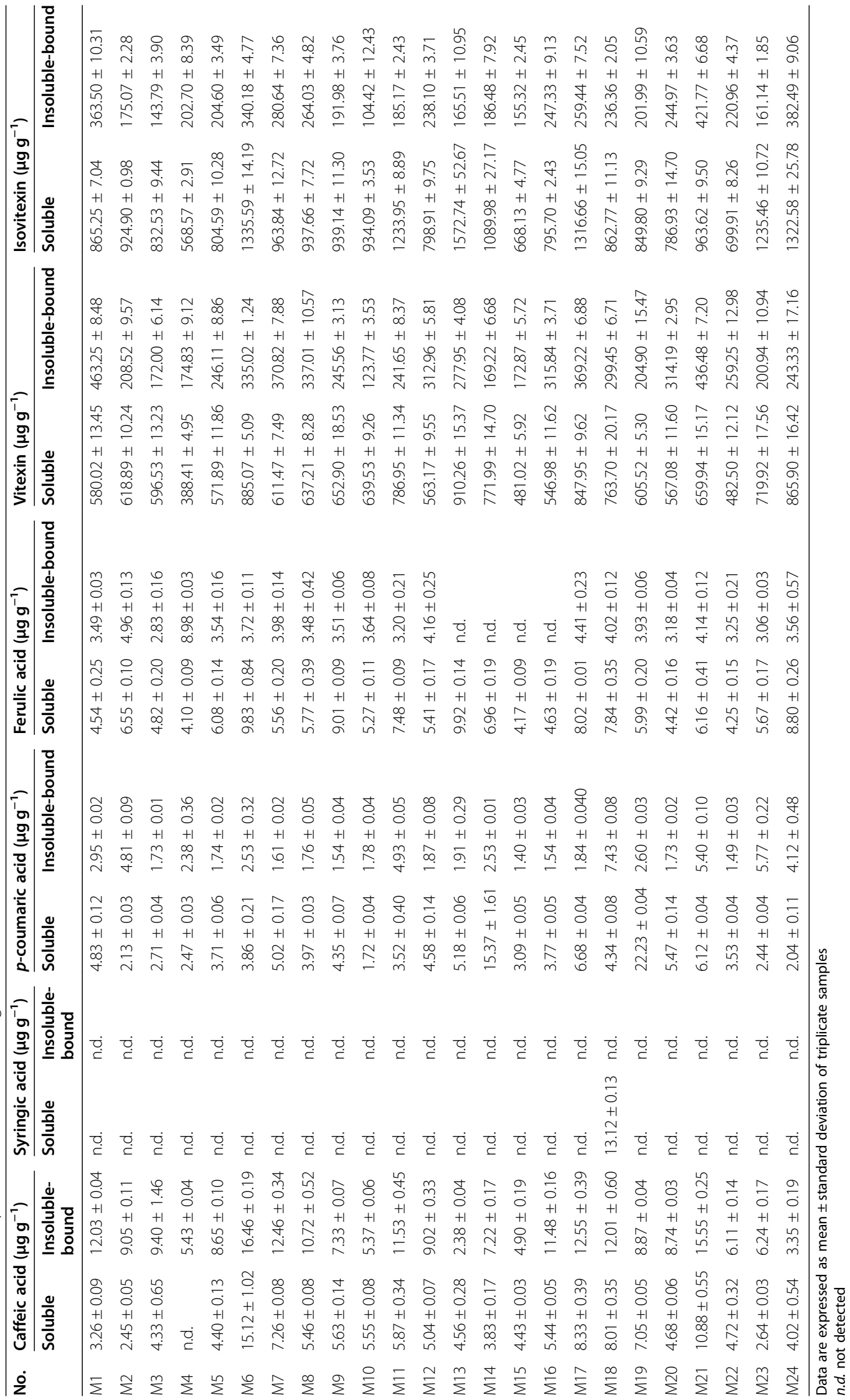




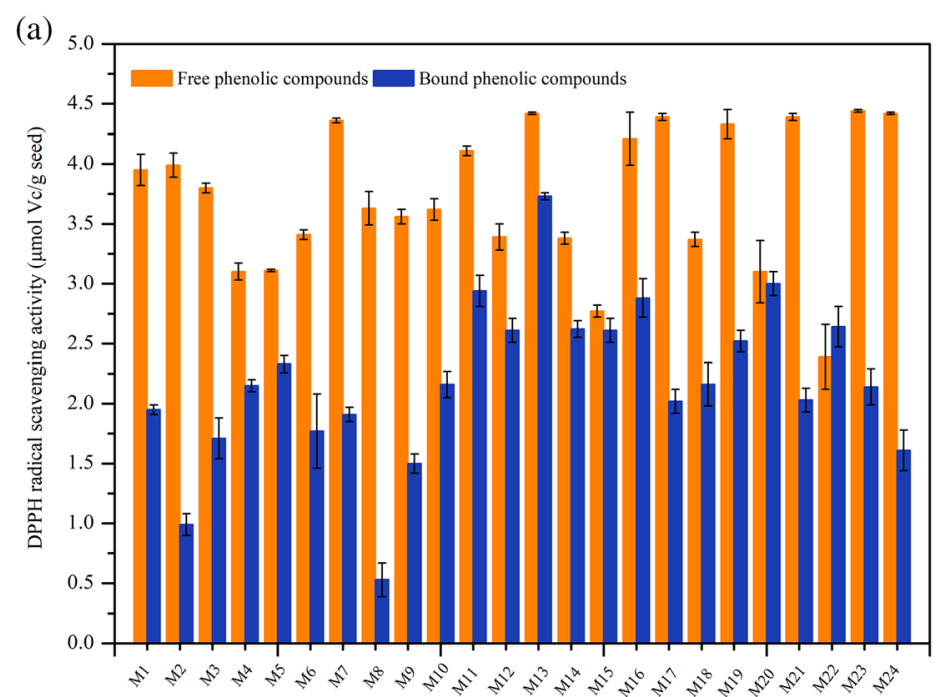

(b)

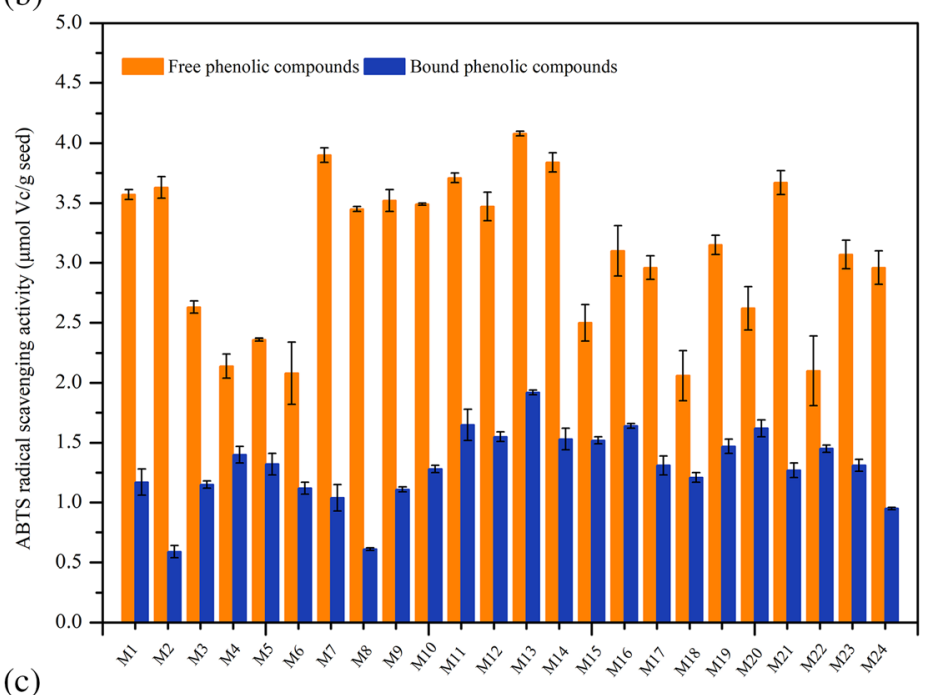

(c)

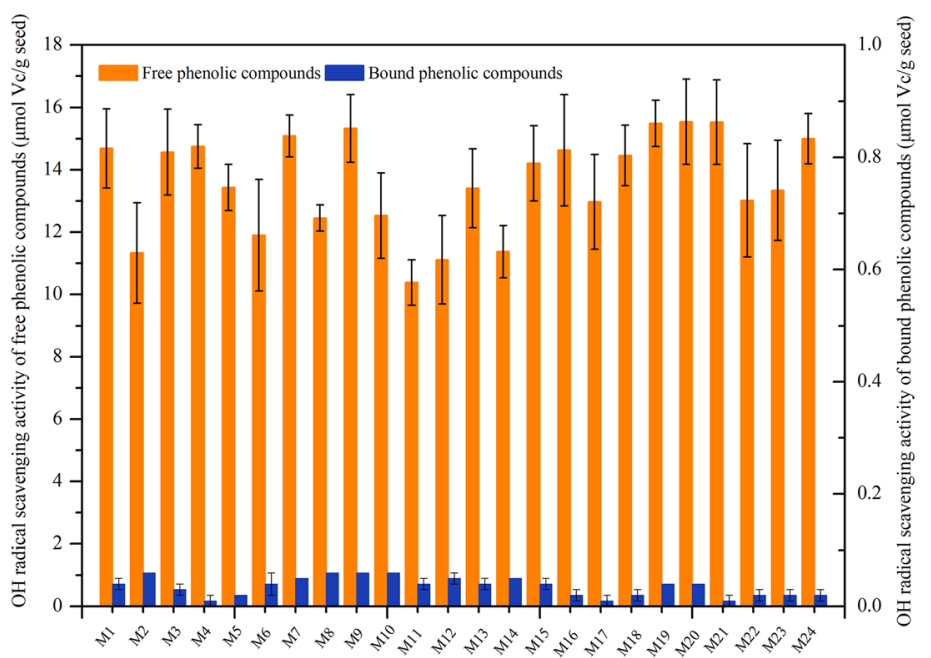

Fig. 4 Antioxidant activities of different mung bean genotypes (mean $\pm S D, n=3$ ), a DPPH radical scavenging activity; $\mathbf{b}$ ABTS radical cation scavenging activity; c hydroxyl radical scavenging ability. Results were expressed as $\mu \mathrm{mol} \mathrm{VC} / \mathrm{g}$ 
among all mung beans in the contents of both soluble and insoluble-bound flavonoids. The vitexin and isovitexin contents in the soluble fractions of mung beans are higher than that in the insoluble-bound fractions. The contents of individual phenolic acids in different bean varieties are also shown in Table 4. Contrary to flavonoids, the contents of phenolic acids in the soluble fractions are lower than that in the insolublebound fractions. Shi et al. (2016) also reported that the average content of bound phenolic acids in the mung bean samples accounted for $89.8 \%$ of the total amount of phenolic acids. Insoluble-bound phenolic compounds can survive upper gastrointestinal digestion and are released from the colon by the effect of microorganism. Results suggested that caffeic acid was the major phenolic acid in mung bean cultivars, ranged from 2.45 to $15.12{\mu g^{-1}}^{-1}$ in the soluble fractions and from 2.38 to $16.46 \mu^{-1} g^{-1}$ in the insolublebound fractions, respectively. Caffeic acid is an effective scavenger of the $\mathrm{ABTS}^{+}$and DPPH radicals, which has strong antioxidant activity (Gülin 2006). Syringic acid was not detected in all mung bean varieties except M18. Flavonoids and phenolic acids are regarded as the major compounds contributing to the total antioxidant activities of mung bean seeds (Shi et al. 2016).

\section{Antioxidant activity}

The results of antioxidant activities are presented in Fig. 4. Soluble phenolic compounds showed stronger antioxidant activity than insoluble-bound phenolic compounds. M23 (Jilv 9025) exhibited the strongest DPPH free radical scavenging ability (Fig. 4a) for soluble phenolic compounds $(4.44 \mu \mathrm{mol} / \mathrm{g})$. At the same time, M13 had the strongest DPPH free radical scavenging ability for the insoluble-bound fraction $(3.73 \mu \mathrm{mol} / \mathrm{g})$. The antioxidant activity can be influenced by many factors and cannot be fully described with one single method. These commonly used methods have their advantages and disadvantages for measuring antioxidant activity. Therefore, in this study, the radical scavenging performance was also evaluated by using the ABTS radical cation and hydroxyl radical assays. Regardless of the soluble or insoluble-bound phenolic compounds, M13 (Suheilv 1) genotype showed the highest ABTS radical scavenging ability (Fig. 4b). The result showed that the ability of soluble phenolic compounds to scavenge hydroxyl radicals ranged from 10.38 to $15.54 \mu \mathrm{mol} / \mathrm{g}$ (Fig. 4c). However, the insoluble-bound phenolic compounds exhibited significantly lower hydroxyl radical scavenging activity. Free radicals will seize the electrons of biomolecules, causing the biomolecules to be altered and cause various diseases, such as inflammation, aging, and cardiovascular diseases. Phenolic compounds can act as hydrogen or electron donors when reacting with oxidative substances (Luo et al. 2016). Therefore, they present strong free radical scavenging activity and antioxidant activity. In general, results indicated that the black seed coat mung bean genotype M13 from our lab presented the strongest antioxidant activity.

\section{Correlation of antioxidant activity with the contents of soluble phenolic compounds and flavonoids}

As shown in Table 5, soluble phenolic content has significantly high correlation with DPPH $\left(r^{2}=0.713\right)$ and ABTS $\left(r^{2}=0.665\right)$ radical scavenging activities. Flavonoid content is significantly correlated with DPPH $\left(r^{2}=\right.$ $0.463)$ radical scavenging activity. No evident correlation is observed between hydroxyl radical scavenging ability and phytochemical contents. A high correlation between the content of phenolic compounds and antioxidant activity has also been previously demonstrated by Shi et al. (2016).

\section{Principal component analysis}

Data of phenolic compounds content, flavonoid content and antioxidant activities of the 24 mung bean genotypes were subjected to principal component analysis (PCA). As shown in Fig. 5, the first two principal components explained $66.1 \%$ of the total variation $(\mathrm{R} 2 \mathrm{X}[1]=37.9 \%$ and $\mathrm{R} 2 \mathrm{X}[2]=28.2 \%)$. The PCA scatter plot revealed the dispersion between the 24 mung bean genotypes. M13 genotype had the largest deviation from the other genotypes, presenting the highest antioxidant activity, phenolic compounds content and flavonoid contents. The longest distance between M13 and M8 showed significant differences in terms of phytochemical contents and antioxidant activities. Principal component analysis indicated that although different mung beans had similar growth environment, they could show significantly differences in phytochemical and antioxidant properties because of their different genotypes. The 24 mung beans were classified into four groups. Group 1 was characterized by high levels of TFC, phenolic contents, DPPH and ABTS free radical scavenging abilities, which contained only M13. Group 2 contained M4, M5, M15, M18 and M22. These genotypes mainly presented similar antioxidant activity. Results of PCA showed

Table 5 Correlation analysis between antioxidant activity and phytochemicals contents

\begin{tabular}{llll}
\hline & DPPH & ABTS $^{+}$ & $\mathbf{O H}^{-}$ \\
\hline Flavonoid content & $0.463^{*}$ & 0.334 & -0.111 \\
Content of soluble phenolic compounds & $0.713^{* *}$ & $0.665^{* *}$ & 0.004 \\
\hline
\end{tabular}

** Significant at $p<0.01$

* Significant at $p<0.05$ 


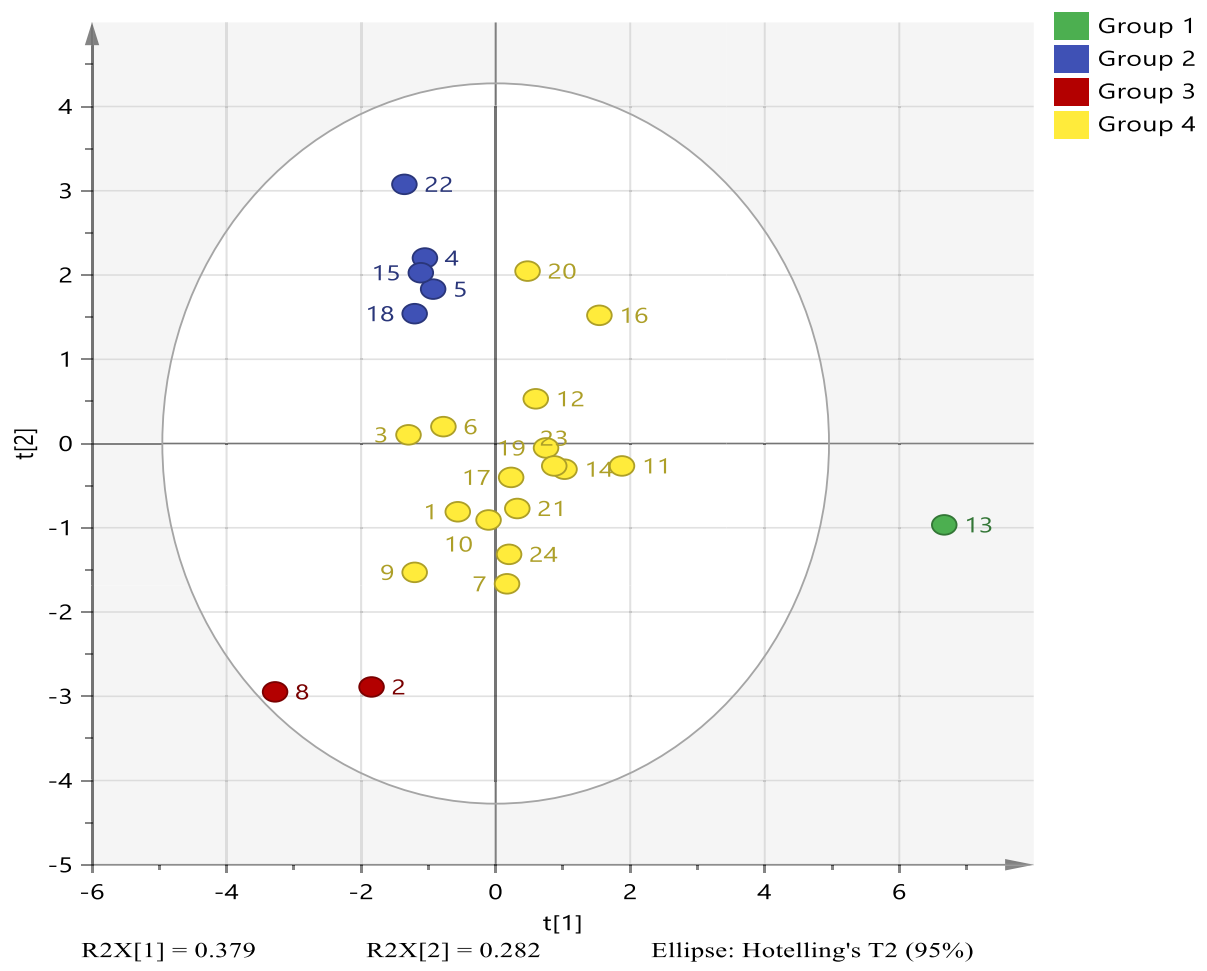

Fig. 5 Principal component analysis based on the phenolic compounds content, flavonoid content and antioxidant activities of 24 mung bean genotypes

satisfactory separation of phenolic compounds and antioxidant activity of these genotypes, indicating that M13 is significantly different from other mung bean genotypes, and implying its potential nutritional and functional values in food processing. Results of this study could provide a good reference for the selection of mung bean genotypes in food production and processing.

\section{Conclusions}

In this study, the nutritional composition, phytochemicals contents and correlations between phytochemical compounds and antioxidant activities of 24 mung bean genotypes from four provinces in China were investigated. The nutritional composition and phytochemical properties of 24 mung bean genotypes are different from each other. Starch, protein, fat, ash and water-soluble polysaccharide ranged from 39.54 to $60.66,17.36$ to $24.89,4.24$ to 12.18 , 2.78 to 3.53 and 1.99 to $2.96 \mathrm{~g} / 100 \mathrm{~g}$ respectively. M13 (Suheilv 1) showed the highest content of phytochemicals contents, such as flavonoids ( $3.52 \mathrm{mg} \mathrm{RE} \mathrm{g}^{-1}$ ), soluble

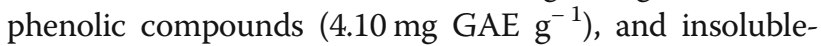
bound phenolic compounds (1.50 $\mathrm{mg} \mathrm{GAE} \mathrm{g}^{-1}$ ). Vitexin and isovitexin were identified by HPLC as the major phenolic compounds in all mung bean genotypes. M13 showed the highest vitexin $\left(910.26{\mu g^{-1}}^{-1}\right.$ and isovitexin $\left(1572.74 \mu \mathrm{g} \mathrm{g}^{-1}\right)$ contents in the soluble fractions of all studied mung beans. Different assays were performed to judge the antioxidant activity of mung bean genotypes, and M13 exhibited strong DPPH and ABTS radical scavenging activities. According to principal component analysis, 24 mung bean samples were classified into four groups based on their phenolic compounds contents and antioxidant activity. The black seed coat mung bean genotype M13 could be used as a superior variety with high antioxidant capacity for functional food production and processing. Overall, this work provides useful information for the potential future application of different mung bean genotypes as source of functional and healthy food. More intensive studies are needed to identify the most effective chemical components in these investigated genotypes.

\section{Abbreviations}

GAE: Gallic acid equivalents; RE: Rutin equivalents; HPLC: High-performance liquid chromatography; DPPH: 2, 2-diphenyl-1-picrylhydrazyl; ABTS: 2, 2azinobis (3-ethylbenzothiazoline-6-sulfonic acid) diammonium salt; FA: Fatty acid; WSP: Water-soluble polysaccharide; TFC: Total flavonoid content; PCA: Principal component analysis

\section{Acknowledgements}

We wish to thank Dr. Wang Jialei from Central Laboratory in Jiangsu Academy of Agricultural Sciences for her help in the HPLC analysis.

\section{Authors' contributions}

Wang F. and Huang L. conducted the experiments, analyzed the data and drafted the manuscript. Yuan X. and Zhang X. helped to process the data. Guo L. took care of the production of the samples. Chen X. and Xue C. 
supervised the project, conceived the project idea and reviewed the manuscript. All authors have read and approved the final manuscript.

\section{Funding}

This work was financed by earmarked fund for China Agriculture Research System (CARS-08-G15) and Jiangsu Agricultural Science and Technology Innovation Fund (CX (20) 2015).

\section{Availability of data and materials}

The data presented in this study are available on request from the corresponding author.

\section{Declarations}

\section{Ethical approval and consent to participate} Not applicable.

\section{Consent for publication}

Not applicable.

\section{Competing interests}

The authors declare that they have no competing interests.

\section{Author details}

${ }^{1}$ Institute of Industrial Crops, Jiangsu Academy of Agricultural Sciences, Nanjing, Jiangsu, China. ${ }^{2}$ College of Food Science and Engineering, Nanjing University of Finance and Economics, Nanjing, Jiangsu, China. ${ }^{3}$ School of Food and Biological Engineering, Jiangsu University, Zhenjiang, Jiangsu, China.

Received: 16 July 2021 Accepted: 31 August 2021

\section{Published online: 09 October 2021}

\section{References}

Alshikh, N., de Camargo, A. C., \& Shahidi, F. (2015). Phenolics of selected lentil cultivars: Antioxidant activities and inhibition of low-density lipoprotein and DNA damage. Journal of Functional Foods, 18, 1022-1038.

Anwar, F., Latif, S., Przybylski, R., Sultana, B., \& Ashraf, M. (2007). Chemical composition and antioxidant activity of seeds of different cultivars of mung bean. Journal of Food Science, 72, 503-510.

AOAC (1990). Official methods of analysis, (15th ed., ). Association of Official Analytical Chemists.

Chai, W. M., Ou-Yang, C., Huang, Q., Lin, M. Z., Wang, Y. X., Xu, K. L., ... Pang, D. D. (2018). Antityrosinase and antioxidant properties of mung bean seed proanthocyanidins: Novel insights into the inhibitory mechanism. Food Chemistry, 260, 27-36.

Connolly, A., O'Keeffe, M. B., Piggott, C. O., Nongonierma, A. B., \& FitzGerald, R. J. (2015). Generation and identification of angiotensin converting enzyme (ACE) inhibitory peptides from a brewers' spent grain protein isolate. Food Chemistry, 176, 64-71

de Camargo, A. C., Regitano-d'Arce, M. A. B., Gallo, C. R., \& Shahidi, F. (2015) Gamma-irradiation induced changes in microbiological status, phenolic profile and antioxidant activity of peanut skin. Journal of Functional Foods, 12 $129-143$

Du, M. X., Xie, J. H., Gong, B., Xu, X., Tang, W., Li, X., .. Xie, M. Y. (2018). Extraction, physicochemical characteristics and functional properties of mung bean protein. Food Hydrocolloids, 76, 131-140.

Ganesan, K., \& Xu, B. (2018). A critical review on phytochemical profile and health promoting effects of mung bean (Vigna radiata). Food Science and Human Wellness, 7, 11-33.

Gülin, I. (2006). Antioxidant activity of caffeic acid (3,4-dihydroxycinnamic acid). Toxicology, 217, 213-220.

Jung, M. Y., Jeon, B. S., \& Bock, J. Y. (2002). Free, esterified, and insoluble-bound phenolic acids in white and red Korean ginsengs (Panax ginseng C.a. Meyer), Food Chemistry, 79, 105-111.

Khaket, T. P., Dhanda, S., Jodha, D., \& Singh, J. (2015). Purification and biochemical characterization of dipeptidyl peptidase-II (DPP7) homologue from germinated Vigna radiata seeds. Bioorganic Chemistry, 63, 132-141.

King, A., \& Young, G. (1999). Characteristics and occurrence of phenolic phytochemicals. Journal of the American Dietetic Association, 99, 213-218.
Lai, F. R., Wen, Q. B., Li, A., Wu, L., \& Li, H. (2010). Antioxidant activities of watersoluble polysaccharide extracted from mung bean (Vigna radiata L.) hull with ultrasonic assisted treatment. Carbohydrate Polymers, 81, 323-329.

Lee, J. H., Jeon, J. K., Kim, S. G., Kim, S. H., Chun, T., \& Imm, J. (2011). Comparative analyses of total phenols, flavonoids, saponins and antioxidant activity in yellow soy beans and mung beans. International Journal of Food Science \& Technology, 46, 2513-2519.

Liu, C., Chen, X., Wang, S., Wang, L., Sun, L., Mei, L., \& Xu, N. (2006). The genetic diversity of mungbean germplasm in China. Journal of Plant Genetic Resources, 7, 459-463 (in Chinese with English abstract).

Luo, J., Cai, W., Wu, T., \& Xu, B. (2016). Phytochemical distribution in hull and cotyledon of adzuki bean (Vigna angularis L.) and mung bean (Vigna radiate $\mathrm{L}$.), and their contribution to antioxidant, anti-inflammatory and antidiabetic activities. Food Chemistry, 201, 350-360.

Mattila, P., Pihlava, J. M., \& Hellström, J. (2005). Contents of phenolic acids, alkyland alkenylresorcinols, and avenanthramides in commercial grain products. Journal of Agricultural and Food Chemistry, 53, 8290-8295.

Randhir, R., \& Shetty, K. (2007). Mung beans processed by solid-state bioconversion improves phenolic content and functionality relevant for diabetes and ulcer management. Innovative Food Science \& Emerging Technologies, 8, 197-204.

Shi, Z., Yao, Y., Zhu, Y., \& Ren, G. (2016). Nutritional composition and antioxidant activity of twenty mung bean cultivars in China. The Crop Journal, 4, 398-406.

Soucek, J., Skvor, J., Pouckova, P., Matougek, J., Slavik, T., \& Matousek, J. (2005). Mung bean sprout (Phaseolus aureus) nuclease and its biological and antitumor effects. Neoplasma, 53, 402-409.

Tang, D., Dong, Y., Ren, H., Li, L., \& He, C. (2014). A review of phytochemistry, metabolite changes, and medicinal uses of the common food mung bean and its sprouts (Vigna radiata). Chemistry Central Journal, 8, 1-9.

Thiex, N. J., Manson, H., Anderson, S., \& Persson, J. A. (2002). Determination of crude protein in animal feed, forage, grain, and oilseeds by using block digestion with a copper catalyst and steam distillation into boric acid: Collaborative study. Journal of AOAC International, 85, 309-317.

Wang, L., Bai, P., Yuan, X., Chen, H., Wang, S., Chen, X., \& Cheng, X. (2018). Genetic diversity assessment of a set of introduced mung bean accessions (Vigna radiata L.). The Crop Journal, 6, 207-213.

Wang, Y. K., Zhang, X., Chen, G. L., Yu, J., Yang, L. Q., \& Gao, Y. Q. (2016). Antioxidant property and their free, soluble conjugate and insoluble-bound phenolic contents in selected beans. Journal of Functional Foods, 24, 359-372.

Xiao, Y., Wang, L. X., Rui, X., Li, W., Chen, X. H., Jiang, M., \& Dong, M. S. (2015). Enhancement of the antioxidant capacity of soy whey by fermentation with lactobacillus plantarum B1-6. Journal of Functional Foods, 12, 33-44.

Xie, J. H., Dong, C. J., Nie, S. P., Li, F., Wang, Z. J., Shen, M. Y., \& Xie, M. Y. (2015). Extraction, chemical composition and antioxidant activity of flavonoids from Cyclocarya paliurus (Batal.) Iljinskaja leaves. Food Chemistry, 186, 97-105.

Yang, Q. Q., Ge, Y. Y., Gunaratne, A., Kong, K. W., Li, H. B., Gul, K., ... Gan, R. Y. (2020). Phenolic profiles, antioxidant activities, and antiproliferative activities of different mung bean (Vigna radiata) varieties from Sri Lanka. Food Bioscience, 37, 100705.

Yao, Y., Yang, X. S., Tian, J., Liu, C. Y., Cheng, X. Z., \& Ren, G. X. (2013). Antioxidant and antidiabetic activities of black mung bean (Vigna radiata L.). Journal of Agricultural and Food Chemistry, 61, 8104-8109.

Yao, Y., Zhu, Y. Y., \& Ren, G. X. (2016). Antioxidant and immunoregulatory activity of alkali-extractable polysaccharides from mung bean. International Journal of Biological Macromolecules, 84, 289-294.

Yates, C. M., Calder, P. C., \& Rainger, G. E. (2014). Pharmacology and therapeutics of omega-3 polyunsaturated fatty acids in chronic inflammatory disease. Pharmacology \& Therapeutics, 141, 272-282.

Zhang, X. W., Shang, P. P., Qin, F., Zhou, Q., Gao, B. Y., Huang, H. Q., ... Yu, L. L. (2013). Chemical composition and antioxidative and anti-inflammatory properties of ten commercial mung bean samples. LWT-Food Science and Technology, 54, 171-178.

Zuk, M., Szperlik, J., Hnitecka, A., \& Szopa, J. (2019). Temporal biosynthesis of flavone constituents in flax growth stages. Plant Physiology and Biochemistry, $142,234-245$.

\section{Publisher's Note}

Springer Nature remains neutral with regard to jurisdictional claims in published maps and institutional affiliations. 